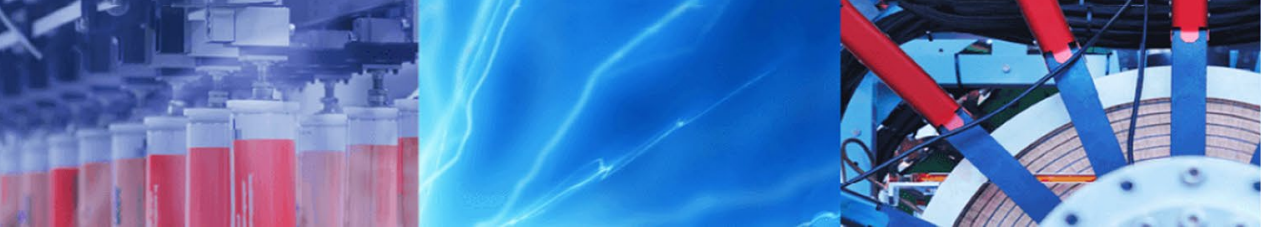

Research Article

\title{
Viscoelastic properties of a novel hydrogel/foam composites for nucleus pulposus replacement
}

\author{
Hassan Mansour Raheem ${ }^{1}$ - Brian Bay ${ }^{2} \cdot$ Skip Rochefort $^{3}$
}

(c) Springer Nature Switzerland AG 2019

\begin{abstract}
Neck and back pathologies cause considerable pain and suffering, and treatment costs tens of billions per year. A common source of problems is degeneration and herniation of the gel-like nucleus pulposus (NP) component of the intervertebral disc, and NP repair/replacement has been a long-term health care goal. We have investigated a novel class of hydrogel/foam composites to identify biocompatible materials with similar viscoelastic characteristics to the native tissue. Low acyl gellan gum $(G)$ and agarose $(A)$ in varying weight percentages were infused into Sugi $^{\circledR}$ cellulose sponge material $(F)$ to produce three candidate materials in addition to those samples without foam. Dynamic oscillatory shear tests and dynamic oscillatory axial compression test tests were conducted on the materials at frequencies between $(f=0.1-10 \mathrm{~Hz})$ to measure elastic (storage) and viscous (loss) moduli in shear and compression conditions. The results show that hydrogel/foam composites show greater viscoelastic properties than hydrogel alone. Various materials of hydrogel and hydrogel/foam composite closely match the viscoelastic properties of native NP tissue.
\end{abstract}

Keywords Agarose hydrogel · Low acyl gellan gum hydrogel · Rheological properties - Dynamic oscillatory shear test . Dynamic oscillatory axial compression test

\section{Introduction}

The third most common reason for surgery in the United States is low back pain (LBP) [1]. The most common cause and symptom of LBP is the degeneration or herniation of the intervertebral disc (IVD) [2]. In addition to a considerable number of people suffering, it is also an economic burden, where the total costs exceed $\$ 100$ billion per year in the United States [3].

The intervertebral disc is a crucial tissue that provides not only flexibility to the torso and neck but also supports loads on the spinal column. Intervertebral discs consist of three distinct regions: the cartilaginous endplates (CEP), the annulus fibrosus (AF), and the nucleus pulposus (NP). The CEP is hyaline cartilage that bonds the adjacent vertebral bones to the AF and NP [4]. The annulus fibrosus surrounds the nucleus pulposus and is composed of many concentric lamellae that consist of type I collagen fibers to support the tension stresses that develop in the AF due to the hydrostatic compression pressure in the NP. The fibers are oriented in each lamella $62^{\circ}-45^{\circ}$ with respect to the spinal column [5]. Nucleus pulposus is a gel-like material with high water content (70-90\% wet weight) and rich in type II collagen and proteoglycans $[6,7]$. The annulus fibrosus and nucleus pulposus perform together as a shock absorption system in the spinal column. Early stages of degeneration involve NP changes such as water loss [8]. Reitmaier et al. [9] study showed that NP replacement and reducing the water content of NP will affect the mechanical behavior

\footnotetext{
$\triangle$ Hassan Mansour Raheem, raheemh@oregonstate.edu | ${ }^{1}$ Ministry of Oil, Midland Refineries Company, Najaf Refinery, Al Najaf, Iraq. ${ }^{2}$ School of Mechanical, Industrial and Manufacturing Engineering, Oregon State University, Corvallis, OR 97331, USA. ${ }^{3}$ School of Chemical, Biological and Environmental Engineering, Oregon State University, Corvallis, OR 97331, USA.
}

SN Applied Sciences (2019) 1:809 | https://doi.org/10.1007/s42452-019-0855-z 
of the intervertebral disc. Currently, there are no treatments for early-stage degeneration. Treatment generally initiates when later stage degeneration and/or acute pathology such as herniation has already occurred. This involves aggressive treatments such as replacing the whole disc with a prosthetic disc [10], or spinal fusion, which immobilizes the spinal segment by permanently joining multiple vertebrae as one solid bone. These treatments require highly invasive surgeries that can alleviate the pain, but they cannot restore the original mechanical and biological properties of a healthy spinal column [11].

To overcome these issues, most efforts have been devoted to developing a minimally invasive surgical approach to treat the degeneration of nucleus pulposus, for example, injecting biocompatible hydrogels using a needle through the annulus fibrosus into the cavity of nucleus pulposus $[12,13]$. The present study will be focused on developing injectable hydrogels (liquid that becomes gel) and controlling their viscoelastic properties using various biocompatible hydrogels and foam aimed to treating degenerative NP.

A hydrogel is a three-dimensional polymeric network which is hydrophilic and cross-linked [14]. Hydrogels have been widely used in biomedical applications $[8,15]$. These hydrogels are highly attractive materials for NP replacement due to their viscoelastic properties which can mimic the viscoelastic behavior of the native NP. Also, hydrogels have high-water content which resembles the natural human NP. To this aim, the hydrogel agarose and low acyl gellan gum will be used in this study. These hydrogels have already been used in tissue engineering as promising materials for NP replacement $[16,17]$.

However, the drawback of using hydrogels without reinforcements is that they tend to fail under mechanical loads, such as compressive loads. Reitmaier et al. [18], demonstrated that pure hydrogel was insufficient for restoring the mechanical behavior of the disc. Also, Teramoto et al. [19], reported that the compression strength of the hydrogel/foam composite, that is a combination of poly(sodium acrylate) (PSA) gel and polyurethane foam, was higher than the hydrogel alone. Beattie and Bay [20] also showed that reinforcing hydrogel with foam leads to enhanced strength of the composite gel. Silva et al. [21] introduced "ionic cross-linked methacrylated gellan gum GG-MA" hydrogels, which exhibited that the mechanical properties of hydrogels were improved due to strong crosslinking, as feasible materials for the degenerative intervertebral disc. Pereira et al. [16] reinforced low and high acyl gellan gum hydrogel (LAGG, HAGG, respectively) with a mixture with microparticles of gellan gum (GG). In their study, they evaluated the mechanical behavior of their innovated materials by performing dynamic mechanical analysis (DMA), and they found that the mechanical properties of gels were enhanced by adding microparticles of GG to the hydrogel samples. They reported that the "25\% HAGG:75\% LAGG (v/v) with $50 \mathrm{mg} / \mathrm{mL}$ MPs GG" hydrogels were the most promising material for replacing the nucleus pulposus.

However, none of these studies evaluated the dynamic axial compression and dynamic shear of the suggested materials for replacing the degenerated NP concurrently. Additionally, it is vital to study the compressive loads because the primary loads that act on the intervertebral disc in routine daily life are compressive loads $[22,23]$. The viscoelastic properties of the hydrogel are more remarkable in shear [24], and consequently, the axial dynamic test and the dynamic shear test should be performed for comparing the viscoelastic properties found in this study to those of synthetic materials and native tissue of nucleus pulposus.

In the current study, various compositions of hydrogels and hydrogel/foam composites were used to study the viscoelastic properties of hydrogels alone and hydrogel/ foam composites regarding storage and loss moduli. In a viscoelastic material, the storage modulus represents the amount of the energy that can be stored, whereas the loss modulus represents the energy dissipated by the viscous material [25]. Since the intervertebral disc experiences both shear and compressive loads in routine daily activities, any substitute materials for the NP should be evaluated under both shear and compression loads. Thus, the dynamic oscillatory shear and dynamic oscillatory axial compression tests must be performed to measure the storage (elastic) moduli $\mathrm{G}^{\prime}$ and $\mathrm{E}^{\prime}$, and the loss (viscous) moduli $\mathrm{G}^{\prime \prime}$ and $\mathrm{E}^{\prime \prime}$ for both tests.

To the best of our knowledge, there are no studies in literature that have investigated the effects of infusing foam into a hydrogel or the viscoelastic behavior of the hydrogel/foam composites in the context of NP replacements. Therefore, the aim of this study is to investigate the effects of reinforcing hydrogels with foam on the viscoelastic behavior of the composite gel, and to develop materials from several synthetic hydrogel/foam composites that mimic the viscoelastic properties of the native NP.

\section{Materials and methods}

\subsection{Materials}

Agarose (A) was purchased from IBI Scientific (IA, USA). KELCOGEL CG-LA "Low Acyl Gellan Gum” (G) material, 
which is pharmaceutical grade, was donated by CP Kelco (GA. USA). Sugi ${ }^{\otimes}$ cellulose sponge material (F) (in a compressed form $600 \mathrm{~g} / \mathrm{m}^{2}$ ) was donated by Kettenbach GmbH \& Co. KG. (Eschenburg, Germany). Sugi ${ }^{\circledR}$ was selected because it has many advantages such as biocompatibility, non-cytotoxicity, non-sensitizing, non-irritating to the skin, and it does not decompose. Furthermore, Sugi ${ }^{\circledast}$ has an open pore structure that can absorb a large amount of liquid [26]. The designation for Sugi ${ }^{\circledR}$ in the following sections will be $(F)$ and the word foam refers to Sugi ${ }^{\oplus}$.

\subsection{Methods}

\subsubsection{Preparation of samples}

In this study, three types of hydrogels with and without foam were prepared as shown in Table 1. The hydrogels without foam were made by putting $100 \mathrm{ml}$ of deionized water (DIW) in a beaker and heating it on a hot plate to $90^{\circ} \mathrm{C}$. Then, the dry powder of the gel was slowly added to the hot DIW. A magnetic stir bar was used while the powder was being added to make a homogenous solution. Disc samples of the hydrogels $(25 \mathrm{~mm}, 4 \mathrm{~mm}$ thickness) were cast by pouring hot liquid hydrogel into a mold made of ultra-high-molecular-weight polyethylene UHMWPE. For the preparation of hydrogels with foam, a $25 \mathrm{~mm}$ diameter compressed foam was soaked into the hot gel solution and was given time to gel. Figure $1 \mathrm{a}, \mathrm{b}$ shows the mold and the samples with and without foam. Later, two types of tests, i.e. dynamic oscillatory shear tests (DOS) and dynamic oscillatory axial compression tests (DOAS) were conducted on the samples with and without foam.

\subsubsection{Dynamic oscillatory shear test (DOS)}

A rotational rheometer DHR-3 (TA Instrument, USA) (Fig. 1C) was used to perform DOS on three hydrogel samples with and without foam $(n=3)$. DOS in the linear viscoelastic (LVE) region (determined to be $0.1 \%$ strain) was performed using a $25 \mathrm{~mm}$ parallel plate geometry (Aluminum disposable plate) at room temperature. DOS
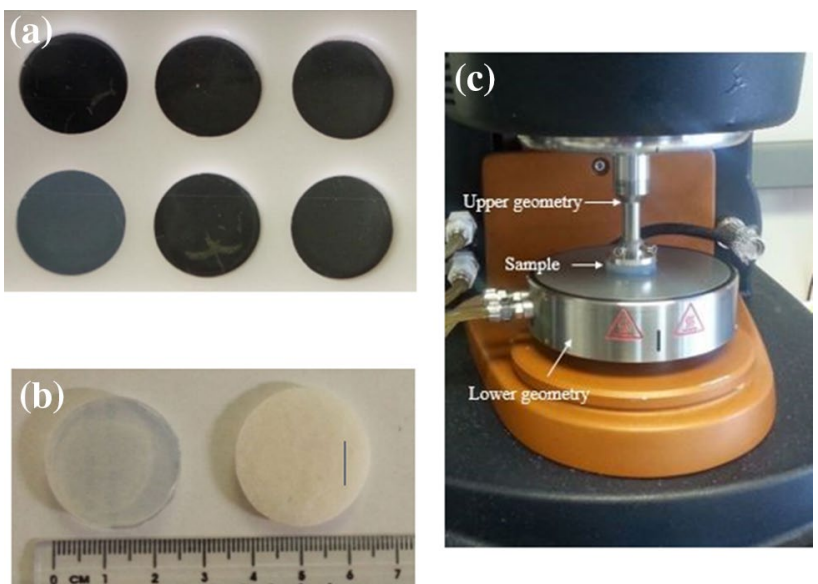

Fig. 1 a The mold made of ultra-high-molecular-weight polyethylene UHMWPE, b samples without (left) and with foam (right), c discovery Hybrid Rheometer "DHR-3" instrument

was performed at physiological relevant frequencies at $f=0.1-10 \mathrm{~Hz}$ [21] with 10 measurement points per decade. Rheological measurements from DOS were made to study the viscoelastic characteristics of the samples in terms of loss $\left(G^{\prime \prime}\right)$ and storage $\left(G^{\prime}\right)$ moduli. A preloading of $<1 \mathrm{~N}$ force was applied to ensure full contact between the sample and plates to avoid artifact on start-up [27]. Three separate discs made from the same patch of hydrogel were used for each set of data and the mean values were used to determine the storage modulus $\mathrm{G}^{\prime}$ and loss modulus $G^{\prime \prime}$. The data were plotted against frequency $(f=0.1-10 \mathrm{~Hz})$.

\subsubsection{Dynamic oscillatory axial compression test (DOAS)}

The procedures for testing the samples using DOAS were the same as those used for DOS except that a $1 \%$ strain deformation, which was determined to be in the linear viscoelastic region for DOAS was used (Note: the DOAS test software is not standard on the DHR-3 and was donated to Dr. Travis Walker by TA Instruments as part of his 2015 Young Rheologist of the year reward). Both storage modulus $\mathrm{E}^{\prime}$ and loss modulus $\mathrm{E}^{\prime \prime}$ were plotted against frequency $(f=0.1-10 \mathrm{~Hz})$. Furthermore, the
Table 1 Designation of the samples

\begin{tabular}{llll}
\hline Materials & Composition of the hydrogel & Designation & \\
\cline { 4 - 4 } & & Without foam & With foam \\
\hline Agarose & 2 wt\% agarose & A2 & A2-F \\
Low acyl gellan gum & 2 wt\% LAGG +1 wt\% agarose & G2A1 & G2A1-F \\
(LAGG) & 2 wt\% LAGG +1.5 wt\% agarose & G2A1.5 & G2A1.5-F \\
\hline
\end{tabular}


phase shift angle (tan $\delta$ ) was calculated for hydrogels with and without foam for both tests. The phase angle is $90^{\circ}$ for purely viscous material and $0^{\circ}$ for purely elastic material. It varies from $0^{\circ}$ to $90^{\circ}$ for viscoelastic materials. The dynamic oscillatory axial compression results of this study will be compared with studies that introduced synthetic materials as replacement materials for the nucleus pulposus $[16,21]$ and with those of the natural nucleus pulposus $[28,29]$.

\subsubsection{Scanning electronic microscopy (SEM)}

The purpose of using scanning electronic microscopy (SEM) was to characterize the structure of the foam that was used in this study. Images of the surface and crosssection texture of dry foam were captured using two small pieces of the foam mounted onto stubs and spin-coated with a thin layer of Palladium using 108 auto sputter coater. SEM images were obtained for each piece.

\subsection{Statistical analysis}

Statistical analysis was performed using a two-sample $t$ test to compare the viscoelastic properties, i.e. storage and loss moduli for both tests, between the samples without and with foam. An XLSTAT add-in software to excel was used to perform the statistical analysis. The differences in viscoelastic properties of comparison were considered statistically significant at $\left({ }^{*} p \leq 0.05\right.$, with a confidence interval 95\%). The data are reported as mean \pm standard deviation (SD).

\section{Results and discussion}

\subsection{Influence of foam on viscoelastic properties}

The viscoelastic characteristics of the hydrogels can be readily tuned by changing the concentrations of the hydrogels in a mixture. For example, when the agarose concentration was increased from 1 to $1.5 \mathrm{wt} \%, \mathrm{G} 2 \mathrm{~A} 1.5$ exhibited greater $G^{\prime}$, and $E^{\prime}$ than the $G 2 A 1$ (Figs. 2a, 3a). For instance, at $f=1 \mathrm{~Hz}$, G' of $\mathrm{G} 2 \mathrm{~A} 1$ was $(10.85 \pm 2.47) \mathrm{kPa}$, whereas, $\mathrm{G}^{\prime}$ for G2A1.5 was (20.06 \pm 1.43$) \mathrm{kPa}$ (Fig. 4a) and $\mathrm{E}^{\prime}(54.48 \pm 7.57)$ $\mathrm{kPa}$ for G2A1 and $\mathrm{E}^{\prime}(94.14 \pm 8.03) \mathrm{kPa}$ for G2A1.5 (Fig. 4b). As it can be seen in Figs. 2 and 3 that the storage moduli ( $G^{\prime}$, $\left.E^{\prime}\right)$ for both hydrogels without and with foam were always higher than the loss moduli $\left(G^{\prime \prime}, E^{\prime \prime}\right)$. The increasing indicates that the elastic behavior was predominant in both samples and tended to be similar to the natural nuclus pulposus behavior [30].

Under dynamic oscillatory axial compression (DOAS), the samples exhibited an increase in both $\mathrm{E}^{\prime}$ and $\mathrm{E}^{\prime \prime}$ with increasing the frequency (Fig. 3) and they also exhibited almost linear viscoelastic behavior. This increasing behavior has already been observed in sheep model [29].

Infusing the hydrogels into the foam led to a significant increase in the storage and loss moduli ( $G^{\prime}$ and $G^{\prime \prime}$ ) for all hydrogels (Fig. 4a) $(p<0.05)$. This increase is likely because the stiffness of the foam is greater than the hydrogels alone. Furthermore, the foam was an opencell foam that absorbed the hydrogel. This suggests this foam could create a network that preserves the hydrogel from soaking out. In contrast, no significant difference was noted in storage and loss moduli E', E" between the (a)

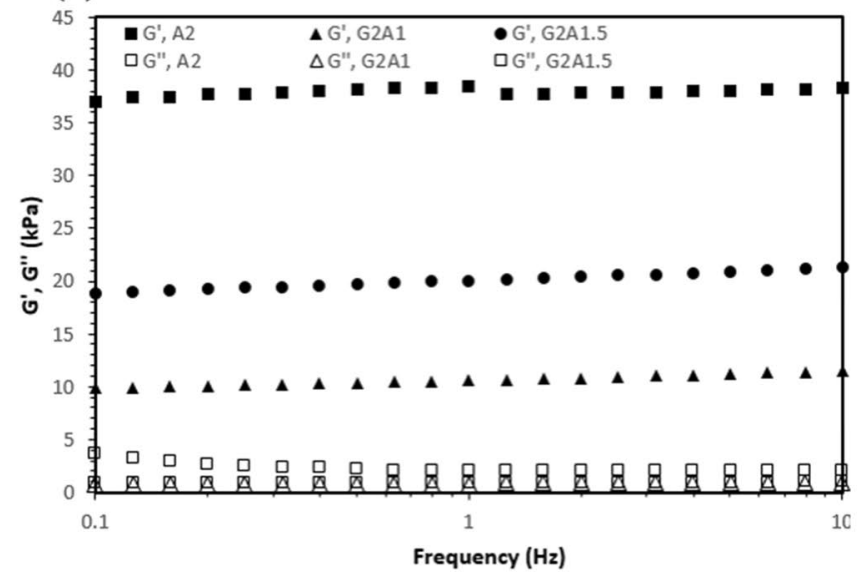

(b)

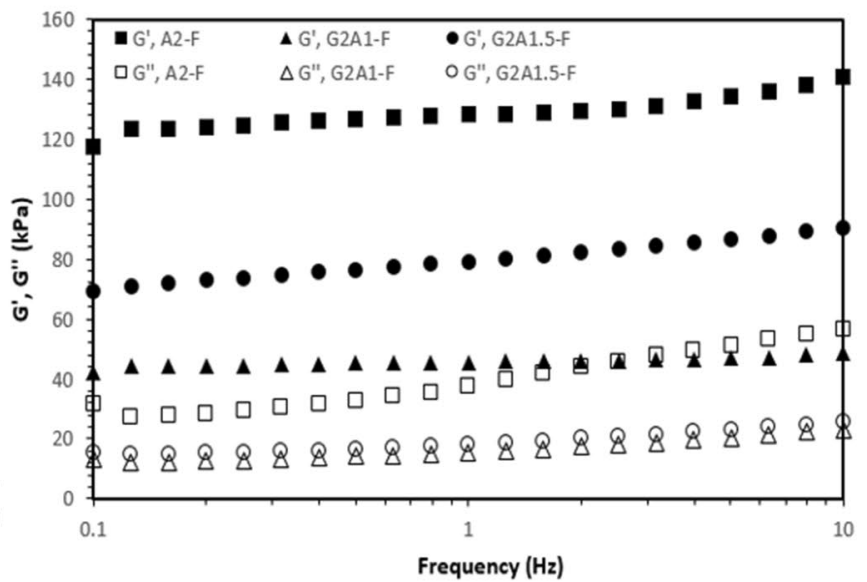

Fig. 2 The storage $G^{\prime}$ and loss $G^{\prime \prime}$ moduli for samples under dynamic oscillation shear test at a $0.1 \%$ strain and over range of frequencies $0.1-10 \mathrm{~Hz}$ a hydrogels without foam. $\mathbf{b}$ Hydrogels/foam comoposites 
(a)

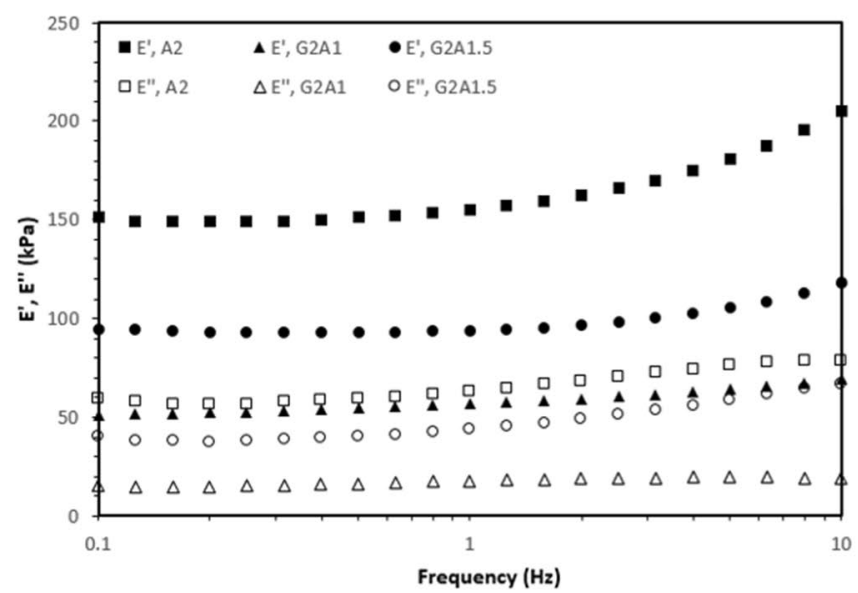

(b)

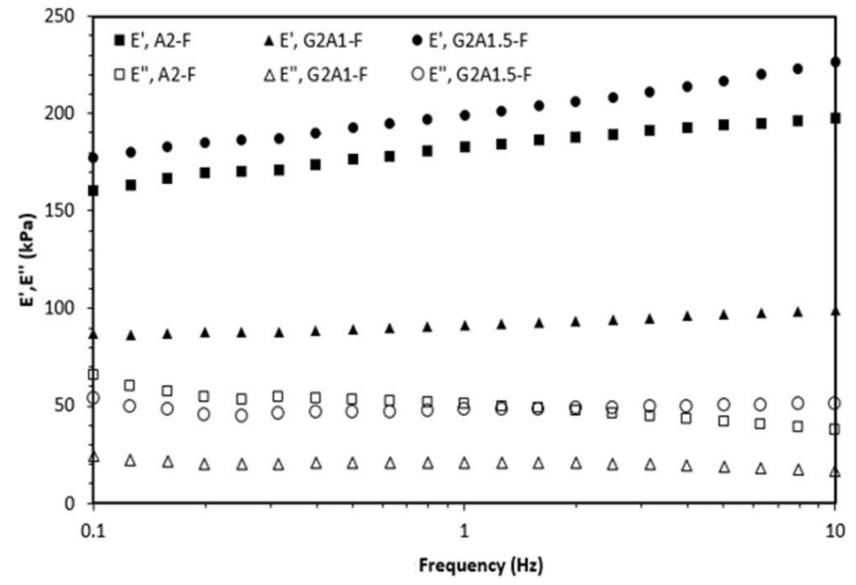

Fig. 3 The storage ( $\left.E^{\prime}\right)$ and loss $\left(E^{\prime \prime}\right)$ moduli for samples under dynimc osciallotry axial compression test at a $1 \%$ strain and over range of frequencies $0.1-10 \mathrm{~Hz}$ a hydrogels without foam. $\mathbf{b}$ hydrogels/foam composites

samples without and with foam, whereas there was a significant difference $(p<0.05)$ in $\mathrm{E}^{\prime}$ between $\mathrm{G} 2 \mathrm{~A} 1.5$ and G2A1.5-F (Fig. 4b).

At $f=1 \mathrm{~Hz}$, the loss factor ( $\tan \delta=\mathrm{E}^{\prime \prime} / \mathrm{E}^{\prime}$ ) was calculated for A2-F, G2A1-F, and G2A1.5-F, such as 0.27, 0.22, and 0.24 , respectively. Even though differences in loss factor were modest among samples, G2A1-F exhibited lower value, which indicates that $G 2 A 1-F$ is more resilient, which the loss of the energy of G2A1-F is less than other materials. Consequently, the aforementioned hydrogels/foam composites could best support torsion, which causes early degeneration in the disc [31] due to their viscoelastic characteristics are greater than hydrogel without foam. The values of storage and loss moduli, at $f=1 \mathrm{~Hz}$, are summarized in Table 2 for both tests DOS, and DOAS.

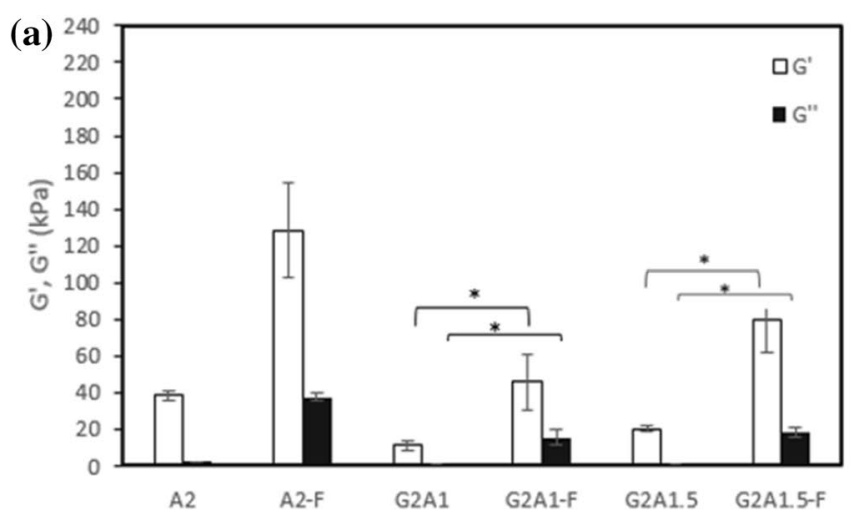

\subsection{Evaluating the viscoelastic properties of the hydrogels/foam composites}

Although the hydrogels were promising as a safe scaffold for nucleus pulposus, there are still many disadvantages that need to be investigated to make the hydrogels feasible materials that adequately replace the NP. The crucial issue is that the hydrogel alone cannot sustain much compression load [18]. Therefore, the mechanical performance of the hydrogels should be improved to retain the viscoelastic behavior for applications of replacing the degenerative NP. As mentioned in the introduction, the microparticles and foam were used to enhance the mechanical properties of the hydrogels. Thus, this study compares the viscoelastic properties of the proposed hydrogels/ foam composites under dynamic compression with synthetic hydrogels $[16,21]$ that have been proposed as a

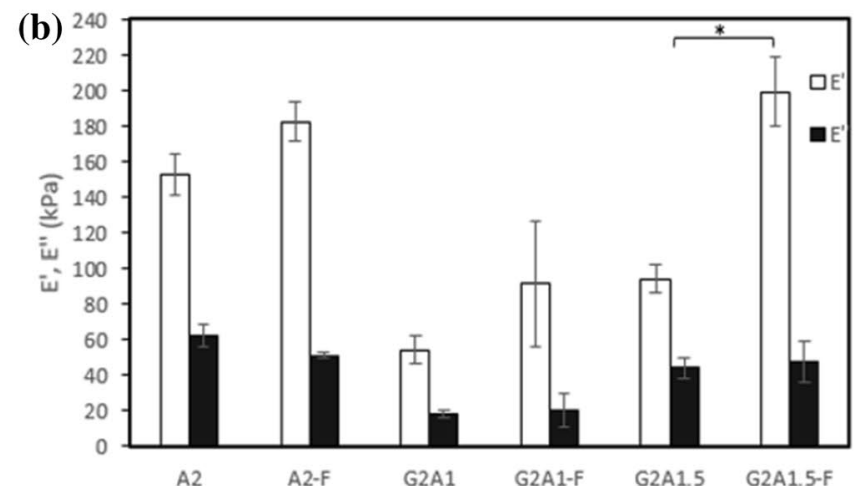

Fig. 4 The storage and loss moduli for samples at $f=1 \mathrm{~Hz}$ a DOS data, $\mathbf{b}$ DOAS data $\left({ }^{*} p \leq 0.05\right)$ 
Table 2 Summarize values of storage $\left(G^{\prime}, E^{\prime}\right)$ and loss $\left(G^{\prime \prime}, E^{\prime \prime}\right)$ moduli in $(\mathrm{kPa})$ for all samples $($ mean \pm SD)

\begin{tabular}{|c|c|c|c|c|}
\hline \multirow[t]{2}{*}{ Sample } & \multicolumn{2}{|c|}{ Storage and loss moduli of DOS test } & \multicolumn{2}{|c|}{ Storage and loss moduli of DOAS test } \\
\hline & $\mathrm{G}^{\prime}(\mathrm{kPa})$ & $\mathrm{G}^{\prime \prime}(\mathrm{kPa})$ & $\mathrm{E}^{\prime}(\mathrm{kPa})$ & $\mathrm{E}^{\prime \prime}(\mathrm{kPa})$ \\
\hline A2 & $38.16 \pm 2.19$ & $2.05 \pm 0.17$ & $152.57 \pm 11.53$ & $62.12 \pm 6.15$ \\
\hline A2-F & $128.48 \pm 25.35$ & $37.45 \pm 2.34$ & $182.68 \pm 11.18$ & $51.14 \pm 1.35$ \\
\hline G2A1 & $10.85 \pm 2.47$ & $0.83 \pm 0.31$ & $54.48 \pm 7.57$ & $18.10 \pm 2.43$ \\
\hline G2A1-F & $45.70 \pm 15.5$ & $15.53 \pm 4.21$ & $91.37 \pm 34.94$ & $20.70 \pm 9.36$ \\
\hline G2A1.5 & $20.06 \pm 1.43$ & $0.84 \pm 0.04$ & $94.14 \pm 8.03$ & $43.99 \pm 5.66$ \\
\hline G2A1.5-F & $79.49 \pm 17.61$ & $18.40 \pm 2.55$ & $199.41 \pm 19.17$ & $48.07 \pm 11.54$ \\
\hline
\end{tabular}

promising material for NP replacement and with studies on natural nucleus for human and sheep [28, 29].

Figure 5 a discloses consistent increases in moduli for all three gels from adding foam reinforcement. However, the shear moduli were also very sensitive to adding the foam, specifically the loss modulus G", which increased 20 times than $G^{\prime \prime}$ of gels without foam. We hypothesized that the structure of the foam (i.e. the fiber orientation through the thickness) plays vital roles in effecting the loss and storage moduli in shear. Therefore, SEM images were considered to characterize the texture structure (morphologies) of the foam and their effects on the moduli of shear loading modes. It is clearly obvious that cellulose fibers of the foam were oriented in cross-section perpendicular on the applied torque, which results to increase the friction among the fibers and it subsequently leads to increase the loss moduli under DOS test. Moreover, the maximum shear plane in the cylinder is considered parallel and perpendicular to the neutral axis which is oriented in the same direction of the fiber. It is clear that the structure of the foam was porous as can be easily distinguished as shown in Fig. 5b, c and it is potentially contributed to increasing the loss moduli. The shear forces greatly affect the loss moduli (G") than the axial compression forces on the hydrogel/foam composites samples as shown in Fig. 6.
Fig. 5 Influence of foam on $G^{\prime}, G^{\prime \prime}, E^{\prime}, E^{\prime \prime}$ moduli (a), SEM images (b, c) of cross-section and surface morphologies of dry foam

(a)

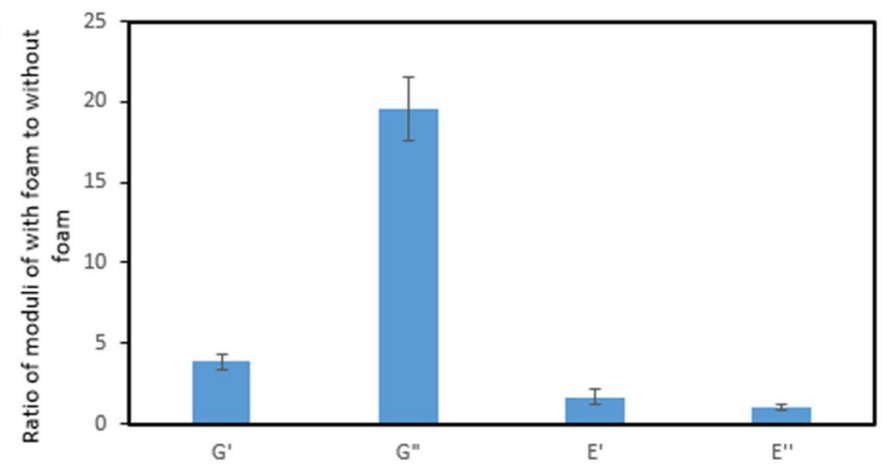

(b)

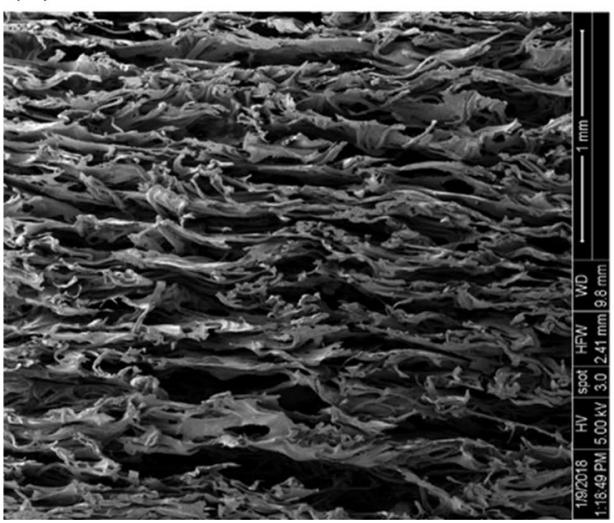

(c)

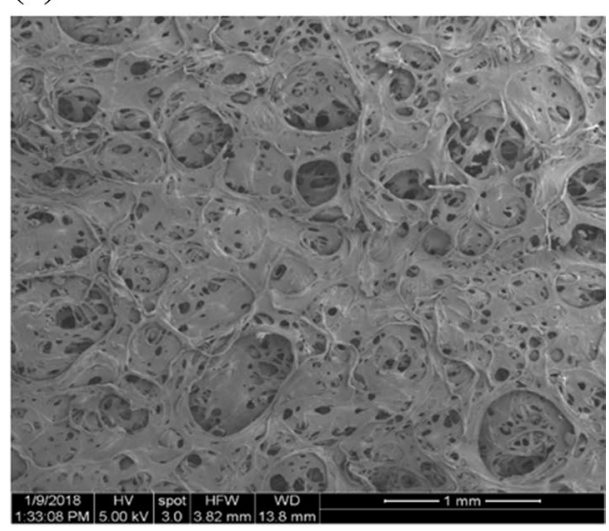


Fig. 6 An illustration of the applied loads on the samples. a The cross-section morphology of the foam. $\mathbf{b}$ An illustration of shear load on the sample (left), and the axial compression load (right). c An illustration of the forces on the plane of loading and at $45^{\circ}$

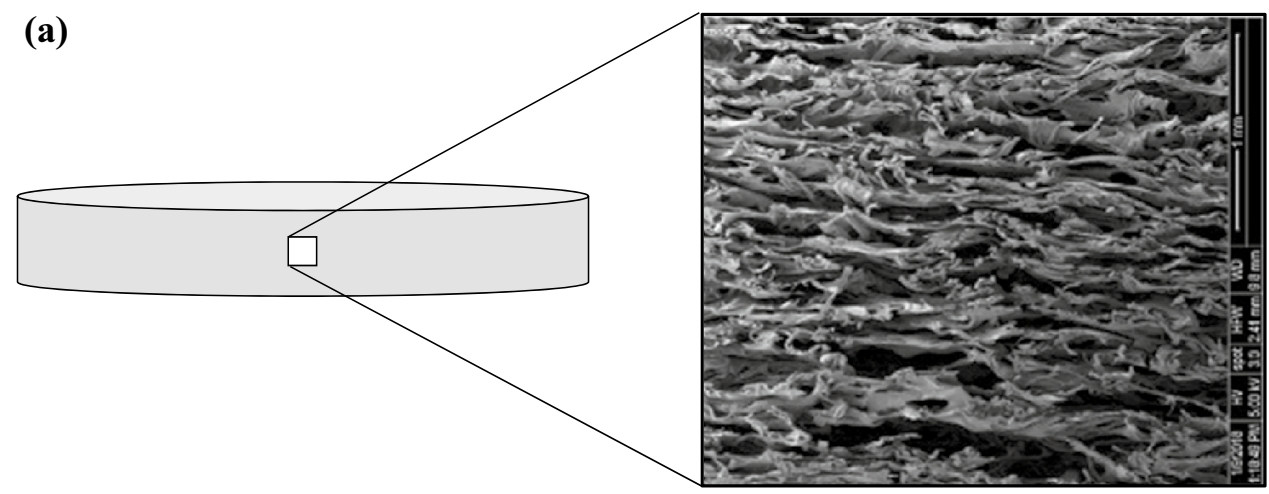

(b)
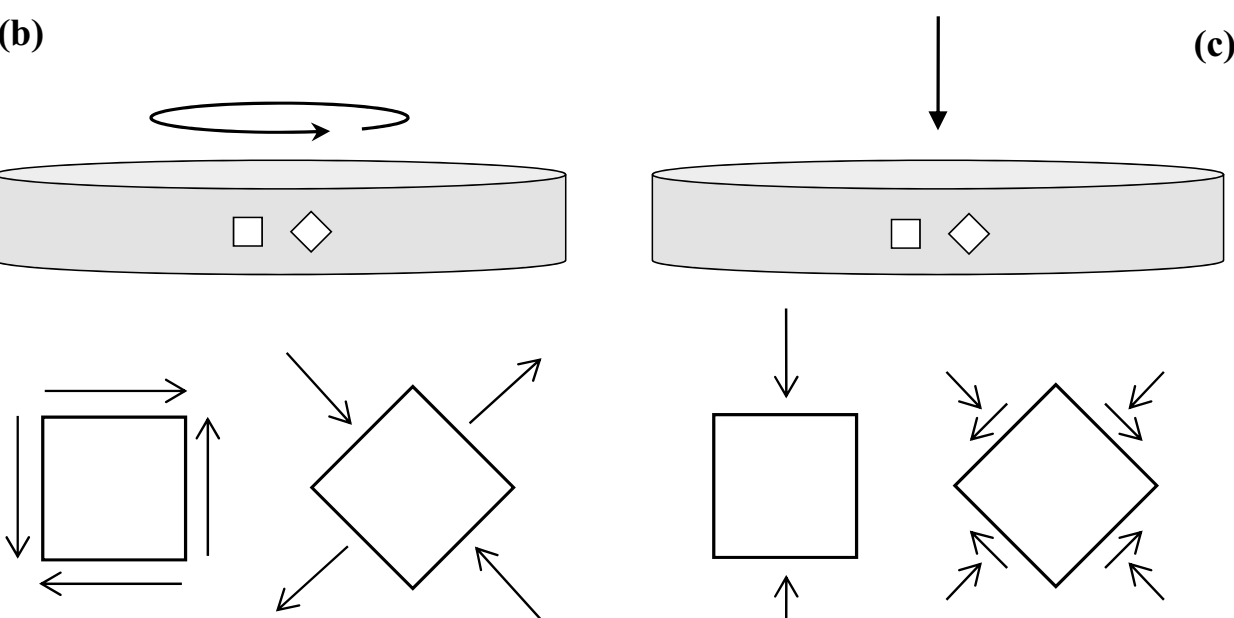

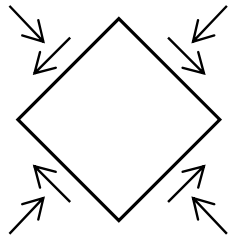

Figure 7 compares the viscoelastic properties of hydrogels and hydrogels/foam composites under dynamic oscillatory axial compression test at $f=1 \mathrm{~Hz}$ between the results of this study and the previous studies [16, $21,28]$. It is worth noting that previous studies [16, $21]$ have reported the loss factor $(\tan \delta)$ and $E^{\prime}$ in their results, therefore; $E^{\prime \prime}$ was calculated using ( $\left.\tan \delta=E^{\prime \prime} / E^{\prime}\right)$ at a frequency $(1 \mathrm{~Hz})$ in order to be compared with our results. For hydrogels without foam, it can be seen that $E^{\prime}$ of G2A1.5 (Fig. 7a) was in line with other studies' results and $E^{\prime \prime}$ exhibited higher value than others $[16,21,28]$, whereas G2A1-F was favorable among other hydrogels/ foam composites, where A2-F and G2A1.5-F exhibited higher viscoelastic properties than the synthetic hydrogels and human nucleus pulposus (Fig. 7b). The measurements for both $\mathrm{E}^{\prime}$ and $\mathrm{E}^{\prime \prime}$ of the hydrogel/foam composites at a frequency of $f=1 \mathrm{~Hz}$ of this study and literature data are summarized in Table 3.

\section{Conclusions}

To the best of the authors' knowledge, this is the first time that the biocompatible foam Sugi ${ }^{\oplus}$ was infused with the hydrogels and proposed to enhance the viscoelastic properties (i.e. storage and loss moduli) of the hydrogel to mimic the viscoelastic properties of the native human NP. In the present work, the viscoelastic properties of the hydrogels were investigated by conducting dynamic oscillatory shear and dynamic oscillatory axial compression tests. Infusing hydrogels into foam consistent increases in moduli for all three gels. However, the shear moduli were also very sensitive to adding the foam, specifically the loss modulus G", which increased 20 times than G" of gels without foam. The hydrogel G2A1-F is a promising material for replacing the native NP, specifically in terms of its ability to replicate the viscoelastic properties of the human NP. 
Fig. 7 Comparing the storage $E^{\prime}$ and loss moduli $E^{\prime \prime}$ of hydrogels at $f=1 \mathrm{~Hz}$ and $1 \%$ strain under DOAS with literature data $[15,20,28]$. a The storage and loss moduli for hydrogels. b The storage and loss moduli for hydrogels/foam composites

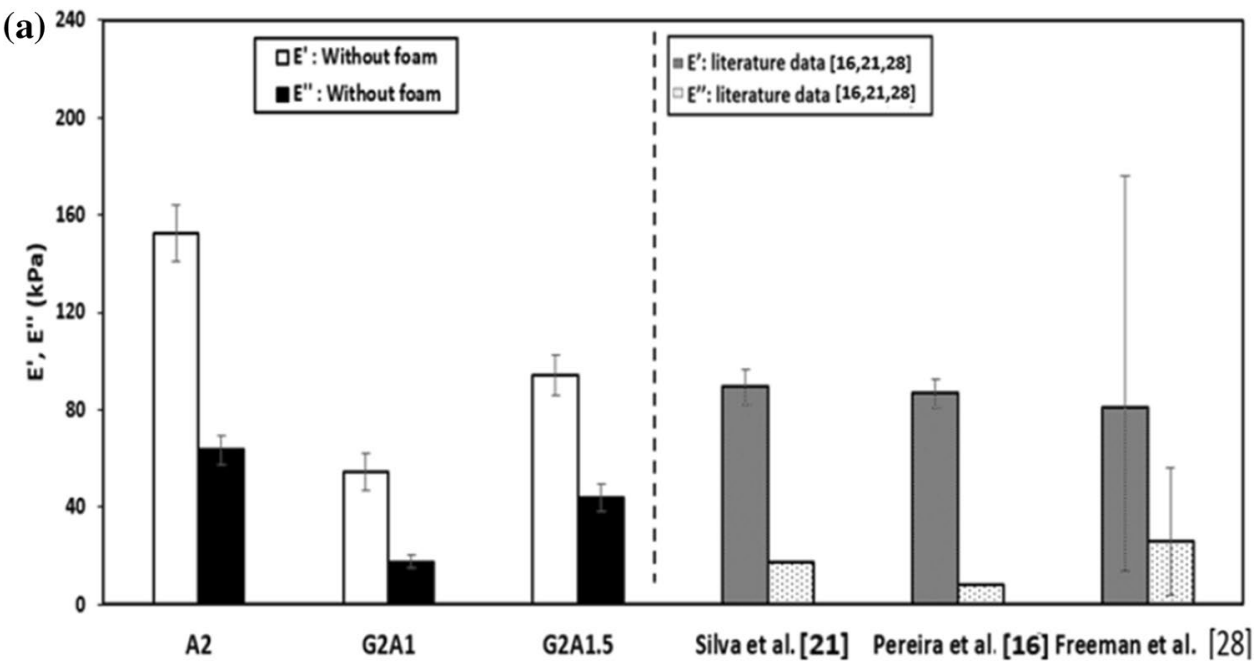

(b)

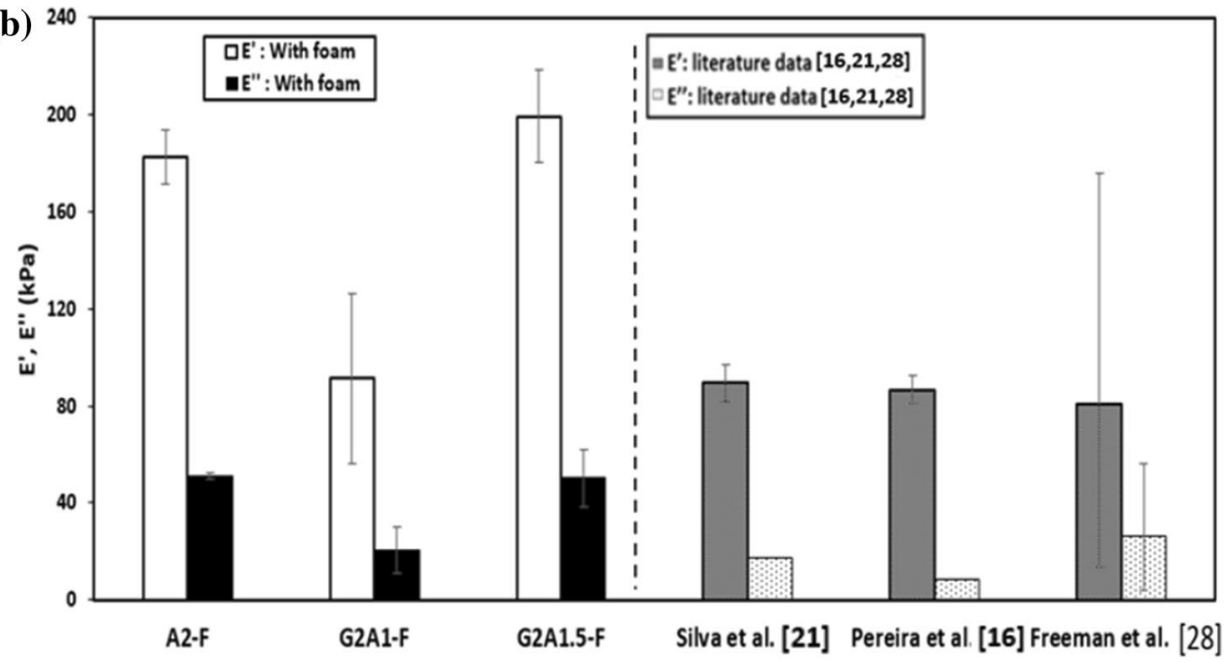

Table 3 Values of storage $\mathrm{E}^{\prime}$ and loss $\mathrm{E}^{\prime \prime}$ moduli measured at $f=1 \mathrm{~Hz}$ of hydrogels/foam composites of the present study compared with the results of previous studies. The data present (mean \pm SD)

\begin{tabular}{|c|c|c|c|c|}
\hline References & Sample & $\mathrm{E}^{\prime}(\mathrm{kPa})$ & & $\mathrm{E}^{\prime \prime}(\mathrm{kPa})$ \\
\hline This study & $\mathrm{A} 2-\mathrm{F}$ & $182.68 \pm 11$ & & $51.14 \pm 1$ \\
\hline This study & G2A1-F & $91.3 \pm 34$ & & $20.7 \pm 9$ \\
\hline This study & G2A1.5-F & $198.21 \pm 14$ & & $50.25 \pm 4$ \\
\hline Freeman et al. [28] ${ }^{\mathrm{a}}$ & Human & 81.01 & & 26.16 \\
\hline \multirow[t]{2}{*}{ Leahy et al. [29] } & Sheep & Fresh & $64 \pm 28$ & $23 \pm 13$ \\
\hline & & Frozen & $83 \pm 20$ & $26 \pm 8$ \\
\hline Silva et al. [21] & GG-MA & $89.5 \pm 7$ & & 17.64 \\
\hline Pereira et al. [16] & $\begin{array}{l}25 \% \mathrm{HAGG}+75 \% \mathrm{LAGG}+50 \% \mathrm{mg} / \\
\mathrm{ml} \mathrm{MPs}\end{array}$ & $86.2 \pm 5$ & & 8.19 \\
\hline
\end{tabular}

${ }^{a}$ Freeman et al. [28] study reported $E^{\prime}$ and $E^{\prime \prime}$ as (median \pm interquartile) for human NP. The mean values and the SD were estimated by using [32] method

\section{Compliance with ethical standards}

Conflict of interest The authors declare that they have no conflict of interest.

\section{References}

1. Andersson GB (1999) Epidemiological features of chronic lowback pain. Lancet 354:581-585 
2. Bogduk N (1991) The lumbar disc and low back pain. Neurosurg Clin N Am 2:791-806

3. Katz JN (2006) Lumbar disc disorders and low-back pain: socioeconomic factors and consequences. JBJS 88:21-24

4. Silva-Correia J, Correia SI, Oliveira JM, Reis RL (2013) Tissue engineering strategies applied in the regeneration of the human intervertebral disk. Biotechnol Adv 31:1514-1531

5. Cassidy J, Hiltner A, Baer E (1989) Hierarchical Structure of the Intervertebral Disc. Connect Tissue Res 23:75-88

6. Ayad S, Weiss JB (1987) In: Jayson MIV (ed) The lumbar spine and back pain, 3rd edn. Churchill Livingstone, London, pp 100-137

7. Buckwalter JA (1995) Aging and degeneration of the human intervertebral disc. Spine 20:1307-1314

8. Leone G, Torricelli P, Chiumiento A, Facchini A, Barbucci R (2008) Amidic alginate hydrogel for nucleus pulposus replacement. J Biomed Mater Res A 84A:391-401

9. Reitmaier S, Shirazi-Adl A, Bashkuev M, Wilke H-J, Gloria A, Schmidt $H$ (2012) In vitro and in silico investigations of disc nucleus replacement. J R Soc Interface 9:1869-1879

10. Taksali S, Grauer JN, Vaccaro AR (2004) Material considerations for intervertebral disc replacement implants. Spine J 4:S231-S238

11. Helen W, Merry CLR, Blaker JJ, Gough JE (2007) Three-dimensional culture of annulus fibrosus cells within PDLLA/Bioglass ${ }^{\oplus}$ composite foam scaffolds: assessment of cell attachment, proliferation and extracellular matrix production. Biomaterials 28:2010-2020

12. Revell PA, Damien E, Di Silvio L, Gurav N, Longinotti C, Ambrosio $L$ (2007) Tissue engineered intervertebral disc repair in the pig using injectable polymers. J Mater Sci Mater Med 18:303-308

13. Berlemann U, Schwarzenbach O (2009) An injectable nucleus replacement as an adjunct to microdiscectomy: 2 year follow-up in a pilot clinical study. Eur Spine J 18:1706-1712

14. Kopeček J (2007) Hydrogel biomaterials: a smart future? Biomaterials 28:5185-5192

15. Joshi A, Fussell G, Thomas J, Hsuan A, Lowman A, Karduna A et al (2006) Functional compressive mechanics of a PVA/PVP nucleus pulposus replacement. Biomaterials 27:176-184

16. Pereira DR, Sliva-Correia Joana, Caridade SG, Oliveria JT, Sousa RA, Salgado AJ et al (2011) Development of gellan gum-based microparticles/hydrogel matrices for application in the intervertebral disc regeneration. Tissue Eng Part C Methods 17:961-972

17. Tasci A, Ettinger L, Ferguson S, Büchler $P$ (2009) The role of agarose mechanical response on the matrix synthesis of nucleus pulposus cells: a pilot study. In: ASME 2009 Summer Bioengineering Conference American Society of Mechanical Engineers, pp 561-562. http://proceedings.asmedigitalcollection.asme. org/proceeding.aspx?articleid=1713213. Accessed 30 Apr 2017

18. Reitmaier S, Wolfram U, Ignatius A, Wilke H-J, Gloria A, MartínMartínez JM et al (2012) Hydrogels for nucleus replacementfacing the biomechanical challenge. J Mech Behav Biomed Mater 14:67-77

19. Teramoto N, Shigehiro O, Ogawa Y, Maruyama Y, Shimasaki T, Shibata M (2014) Polymer foam-reinforced hydrogels inspired by plant body frameworks as high-performance soft matter. Polym J 46:592-597

20. Beattie W, Bay B (2010) Hydrogel composite as a nucleus pulposus replacement designed to resist extrusion while maintaining functional material properties. In: ASME 2010 international mechanical engineering congress and exposition. American Society of Mechanical Engineers, pp 29-33. http://proce edings.asmedigitalcollection.asme.org/proceeding.aspx?artic leid=1615419. Accessed 02 Nov 2016

21. Silva-Correia J, Oliveira JM, Caridade SG, Oliveria JT, Sousa RA, Mano JF et al (2011) Gellan gum-based hydrogels for intervertebral disc tissue-engineering applications. J Tissue Eng Regen Med 5:e97-e107

22. White AA, Panjabi MM (1990) Clinical biomechanics of the spine, 2nd edn. Lippincott, Philadelphia

23. Gloria A, Causa F, De Santis R, Netti PA, Ambrosio L (2007) Dynamic-mechanical properties of a novel composite intervertebral disc prosthesis. J Mater Sci Mater Med 18:2159-2165

24. Ferry JD (1980) Viscoelastic properties of polymers, 3rd edn. Wiley, New York

25. Tanaka E, Aoyama J, Tanaka M, Murata H, Hamada T, Tanne K (2002) Dynamic properties of bovine temporomandibular joint disks change with age. J Dent Res 81:618-622

26. Absorption - Kettenbach GmbH \& Co. KG. http://www.sugis ponge.com/en/material/absorption.html. Accessed 30 Apr 2017

27. Bron JL, Koenderink GH, Everts V, Smit TH (2009) Rheological characterization of the nucleus pulposus and dense collagen scaffolds intended for functional replacement. J Orthop Res 27:620-626

28. Freeman AL, Buttermann GR, Beaubien BP, Rochefort WE (2013) Compressive properties of fibrous repair tissue compared to nucleus and annulus. J Biomech 46:1714-1721

29. Leahy JC, Hukins DWL (2001) Viscoelastic properties of the nucleus pulposus of the intervertebral disk in compression. $J$ Mater Sci Mater Med 12:689-692

30. latridis JC, Weidenbaum M, Setton LA, Mow VC (1996) Is the nucleus pulposus a solid or a fluid? Mechanical behaviors of the nucleus pulposus of the human intervertebral disc. Spine 21:1174-1184

31. Cholewicki J, McGill S, Norman R (1991) lumbar spine loads during the lifting of extremely heavy weights. Med Sci Sports Exerc 23:1179-1186

32. Hozo SP, Djulbegovic B, Hozo I (2005) Estimating the mean and variance from the median, range, and the size of a sample. BMC Med Res Methodol 5:13. https://doi. org/10.1186/1471-2288-5-13

Publisher's Note Springer Nature remains neutral with regard to jurisdictional claims in published maps and institutional affiliations. 